\title{
Questões contemporâneas no campo das políticas educacionais: Produção comunitária, Criminalização da vida e Práticas de liberdade
}

\section{Modern issues in the field of educational policies: community production, criminalization of life and freedom practices}

\author{
Alessandra Speranza Lacaz* \\ Universidade Federal do Espírito Santo-UFES, Vitória, Espírito Santo, Brasil \\ Marcel Romanio** \\ Universidade Federal do Espírito Santo-UFES, Vitória, Espírito Santo, Brasil
}

\section{Suzana Maria Gotardo***}

Universidade Federal do Espírito Santo-UFES, Vitória, Espírito Santo, Brasil

\author{
Ana Lúcia C. Heckert**** \\ Universidade Federal do Espírito Santo-UFES, Vitória, Espírito Santo, Brasil
}

\begin{abstract}
RESUMO
O presente artigo se propõe a analisar políticas que se forjam na educação, tendo em vista os modos de vida contemporâneos operados pela biopolítica em seus tensionamentos entre poder e resistência. A partir de estudo bibliográfico e de indagações advindas de pesquisas que estamos atualmente desenvolvendo em escolas públicas, tomamos duas questões que nos têm inquietado: os modos-comunidade que são produzidos nesse momento histórico e as práticas que configuram o que designamos por criminalização da vida. Procuramos evidenciar as capturas que vêm sendo operadas na educação sob o signo comunidade mediante o uso desse constructo - ligado a uma ideia de participação coletiva - para a legitimação de práticas hegemônicas, ou em favor de políticas de segurança, como a presença cada vez mais frequente da polícia e do aparato/funcionamento judiciário nas escolas, em um contexto marcado pela difusão do medo. Entendemos, todavia, que tais capturas constituem-se em aprimoramentos dos modos capitalísticos de funcionamento, emergindo justamente porque a todo o tempo a vida se re-inventa e foge às modulações.

Palavras-chave: resistência, biopolítica, educação, comunidade, criminalização da vida.
\end{abstract}

\section{ABSTRACT}

This article aims to analyse the politics forged in education, with a view to the contemporary ways of living operated by biopolitics in their tensionings between power and resistance. Based on this, we take two issues that have troubled us in the researches we have developed in schools nowadays: the community-modes produced in this historical moment and the practices that 
shape what we call the criminalization of life. We evince the catches that have been operated in education under the sign of community through the use of this construct - tied to an idea of collective participation - to the legitimacy of hegemonic practices, or in favor of some kind of security, as the increasingly frequent presence of police and judicial apparatus/ functioning in schools, in a context marked by fear diffusion. We believe, however, that such catches are improvements of the capitalistic mode of operation, emerged precisely because, at any time, life is being re-invented and flees from the modulations.

Keywords: resistance, biopolitics, education, community, criminalization of life.

\section{I ntrodução}

Foi a vida, muito mais do que o direito, que se tornou o objeto das lutas políticas, ainda que estas últimas se formulem através de afirmações de direito. O "direito" à vida, ao corpo, à saúde, à felicidade, à satisfação das necessidades, o "direito", acima de todas as opressões ou "alienações", de encontrar o que é e tudo o que pode ser, esse "direito" tão incompreensível para o sistema jurídico clássico, foi a réplica política a todos esses novos procedimentos de poder que, por sua vez, também não fazem parte do direito tradicional da soberania. (FOUCAULT, 2007, p. 158).

Neste trabalho, focalizamos nossas discussões na implementação de políticas que se afirmam sob o slogan do desenvolvimento e da proteção da vida. Porém, será que elas atuam no sentido do que propõem? O que têm produzido essas políticas? A que favorecem? De que proteger a vida? Quais perigos a ameaçam? Como articular práticas de liberdade a políticas fomentadas pela máquina de Estado - o qual, por definição, se constitui como regulador da vida? As políticas de Estado têm visado à construção de tais práticas?

Partindo dessas questões, propomos analisar políticas educacionais contemporâneas, entendendo que estas se produzem no fio da navalha entre práticas que se engendram num sentido de controle da vida e práticas de liberdade que escapam e torcem os mecanismos hegemônicos de captura. Nessa análise, enfocamos dois aspectos que nos têm convocado a pensar: os usos do constructo comunidade e a criminalização da vida nos espaços-tempos escolares.

Iniciaremos com uma breve incursão aos estudos de biopolítica empreendidos por Foucault, entendendo-os como uma ferramenta que nos auxilia na empreitada a que nos propomos. 


\title{
2 Resistência, Poder e a Noção de Biopolítica em Foucault
}

Foucault aponta para os conceitos de biopolítica e biopoder no ultimo capítulo do livro História da Sexualidade Vol. I, impulsionado pelos estudos acerca do poder nos anos 70, conceito que define como:

\begin{abstract}
[...] a multiplicidade de correlações de força imanentes ao domínio onde se exercem e constitutivas de sua organização; o jogo que, através de lutas e afrontamentos incessantes as transforma, reforça, inverte; os apoios que tais correlações de força encontram umas nas outras, formando cadeias ou sistemas ou ao contrário, as defasagens e contradições que as isolam entre si; enfim, as estratégias em que se originam e cujo esboço geral ou cristalização institucional toma corpo nos aparelhos estatais, na formulação da lei, nas hegemonias sociais. (FOUCAULT, 2007, p. 102).
\end{abstract}

Poder, nessa perspectiva, não é tomado como uma instância, algo que se pode adquirir, possuir, trocar, perder, encontrar. Para Foucault só existem exercícios de poder e esses se estabelecem, necessariamente, "em função de uma multiplicidade de pontos de resistência que representam, nas relações de poder, o papel de adversário, de alvo, de apoio, de saliência que permite a preensão" (1985, p. 91). Assim, Foucault traça, ao invés de uma hipótese repressiva acerca do poder, a ideia de uma produção de realidades como efeito entre os jogos de poder (de dominação) e de resistência (de liberdade). (FOUCAULT, 2008a).

Tal autor nos alerta para o fato de que esses nós que se constituem como resistência, contrapontos nas relações de poder, não devem ser pensados em termos de reatividade, mas em seu caráter produtivo. Assim, as resistências:

[...] introduzem na sociedade clivagens que se deslocam, rompem unidades e suscitam reagrupamentos, percorrem os próprios indivíduos, recortando-os e os remodelando, traçando neles, em seus corpos e almas, regiões irredutíveis. (FOUCAULT, 1985, p. 92).

Heckert (2004), a partir de análises empreendidas por Deleuze e Proust, escreve que as resistências são "primeiras", não por virem antes ou serem mais importantes, mas por torcerem e movimentarem as relações de poder, dando um certo ritmo ao jogo. Nesta incessante composição de forças e lutas, podemos afirmar que as resistências não significam somente o enfrentamento das práticas instituídas, mas também expressam as diferentes maneiras com que, ao nos depararmos com suas conformidades, agimos ou deixamos de agir. Consideramos, assim, que a produção operada pelas resistências e seus efeitos, remete à imprevisibilidade inerente ao 
vivo e, desse modo, afirmamos que elas não produzem somente reações sobre os processos já instituídos, mas também fazem deste processo uma criação de outros modos de vida, portanto, assumindo a potência criadora de produção de movimento que o vivo constitui.

Tendo isso em vista, importa frisar três aspectos antes de tratarmos mais diretamente de biopolítica. Primeiro, Foucault não descreve uma sociedade que se dobra passivamente aos imperativos das formas hegemônicas de poder. Segundo, os tensionamentos entre resistências e poder implicam em torcer-se e fazer torcer, ou seja: não é o poder que torce a resistência ou o contrário, ambos se interferem, se conformam nesses jogos. Terceiro, dizer que as resistências atingem e modificam as direções dos exercícios de poder não é enquadrá-las como força reativa: o poder procura sempre mecanismos para contornar as resistências e é nesse jogo que vão sendo criadas realidades. Pensamos, desse modo, em termos de práticas que se produzem, se modificam e se extinguem historicamente por meio de tais embates de força e isso nos é estratégico porque instrumenta a conceber certas construções hegemônicas do contemporâneo que, de algum modo, atuam num sentido de captura e cerceamento da vida como formas não "naturais". Sendo assim, entendemos que tais formas podem perder terreno para práticas mais libertárias, mais afirmativas da vida.

Foucault (2007), ao empreender a distinção do que denomina de poder soberano - força hegemônica nas ditas sociedades feudais dos processos normalizadores que prevalecem nas sociedades disciplinares que se delineiam junto à Revolução Industrial, percebe que não são apenas as práticas de negação e repressão do direito que regulam a vida, mas também o investimento na produção subjetiva ${ }^{1}$, que se utiliza de dispositivos tais como escola, trabalho, igreja, hospital, etc. para definir, normatizar e administrar a vida humana - entendendo que tais estabelecimentos não funcionam apenas como dispositivos disciplinares. A esse poder que investe na vida, ele denominou então de biopoder.

Mas Foucault percebeu ainda, a partir dos séculos XVIII e XIX, que as configurações hegemônicas de poder já não se caracterizavam como poder soberano de punir aos súditos (FOUCAULT, 1975) ou como poder disciplinador regulando a vida dos sujeitos como indivíduos. Assim, passa-se então ao que Foucault constitui como mudança na arte de governar, "pode-se dizer que o velho direito de causar a morte ou deixar viver foi substituído por um poder de causar a vida ou devolver a morte" (FOUCAULT, 2007, p.150). Na figura do Estado, na arte governamental (FOUCAULT, 2008a), organizava-se um conjunto de "planos" para a população, para a vida como espécie, um modo de exercício do poder que ele chamaria de biopolítica.

Para ele, esta arte governamental necessita investir nos processos de liberdade. Em suas palavras: 
Alessandra Speranza Lacaz, Marcel Romanio, Suzana Maria Gotardo,

Ana Lúcia C. Heckert

Questões contemporâneas no campo das políticas educacionais

\begin{abstract}
A nova arte governamental vai se apresentar portanto como gestora da liberdade, não no sentido imperativo "seja livre", com a contradição imediata que esse imperativo pode trazer. Não é o "seja livre" que o liberalismo formula. O liberalismo formula simplesmente o seguinte: vou produzir o necessário para tornar você livre. Vou fazer de tal modo que você tenha a liberdade de ser livre. [...] esse liberalismo que podemos caracterizar como a nova arte de governar formada no século XVIII, implica em seu cerne uma relação de produção/destruição [com a] liberdade [...]. É necessário, de um lado, produzir a liberdade, mas esse gesto mesmo implica que, de outro lado, se estabeleçam limitações, controles, coerções, obrigações apoiadas em ameaças, etc. (FOUCAULT, 2008, p.87).
\end{abstract}

Ao problematizarmos as práticas de liberdade, inseridas num sistema de regras que governa e regula a vida, estaremos tensionando os limites do que Foucault chamou de liberdade, pois segundo ele, o poder só se exerce sobre/por "sujeitos livres", visto que:

A relação de poder e a insubmissão da liberdade não podem, então, ser separadas. O problema central do poder não é o da "servidão voluntária" (como poderíamos desejar ser escravos?): no centro da relação de poder, "provocando-a" incessantemente, encontra-se a recalcitrância do querer e a intransigência da liberdade. (FOUCAULT, 1995, p 244).

Pensarmos que o controle sobre a vida, a partir da noção de biopolítica, nos possibilita também reavaliar as maneiras como se atualizam estes poderes, como se configuram, como atuam sobre a vida e como prevalecem sob a forma hegemônica de um poder constituído. Mas, principalmente, ressaltar os movimentos de liberdade, de um poder constituinte ${ }^{2}$ que põe em xeque as formas vigentes e movimenta, por sua vez, os jogos do poder.

Acreditamos, entre outras proposições que, ao colocarmos em análise a constituição de políticas educacionais contemporâneas - políticas produzidas com os aparatos da máquina de Estado; políticas empreendidas por governos com finalidades partidárias específicas; políticas públicas, tecidas no coletivo para "qualquer um" (BENEVIDES; PASSOS, 2005a; 2005b); estratégias que se operam no chão educacional; movimentos macro e micropolíticos ${ }^{3}$ potencializamos a produção de outros modos de gerir a vida e a si próprio ${ }^{4}$. 


\section{Capitalismo, Biopolítica e a Produção Comunitária}

Uma das pesquisas que desenvolvemos em uma escola pública de educação profissional se propôs a investigar o que designamos por políticas de comunidade. Tais políticas são aqui entendidas como os jogos de força que operam práticas e discursos, o que se faz e o que se diz sob o nome comunidade, tomando tal produção como diretamente vinculadas a composições próprias de um certo tempo, a tensionamentos, a relações de poder talhadas com os instrumentos e com as matérias de um determinado momento histórico. Os apontamentos realizados nesse item são referentes aos estudos e resultados parciais dessa pesquisa.

Numa análise dos processos que ocorrem atualmente em nossa sociedade, entendemo-nos circunstanciados pelas tecnologias biopolíticas, necessárias e compatíveis com o modo de produção hegemônico capitalista - não apenas econômico, financeiro ou social; um modo de produção da vida, uma forma da vida operar. Ao pensarmos a questão da participação social nas engrenagens da biopolítica e do capitalismo, destacamos a configuração peculiar que vem sendo produzida por/sobre os discursos e práticas que envolvem a temática da comunidade.

Com relação a isso, abordaremos três movimentos. Primeiro: às formações capitalísticas é necessário reiterar valores e formas de expressão que garantam sua manutenção como sistema hegemônico. Dentre esses valores, destacam-se o acúmulo, a competitividade, a produtividade, a concorrência e, por conseguinte, o individualismo. $O$ terreno educacional contemporâneo (que não se encontra em separado das demais esferas desse mundo) colabora reafirmando tais valores em grande parte de suas produções. Mas aí entramos na segunda formulação: isso não quer dizer que a comunidade foi abolida dos discursos, que ela foi expurgada. Os aparatos capitalistas se apropriaram de um certo modo-comunidade, que passou a compor com o discurso hegemônico. Assim tem acontecido em muitas produções da/na educação: "atentemo-nos para a comunidade e desse modo formaremos melhor o indivíduo". Ou seja, a comunidade é importante, mas não é nem o foco e nem o fim. Terceiro: nas experiências junto à escola que tomamos como nosso campo de trabalho-pesquisa, são tecidas outras políticas de comunidade, que falam da produção de redes de solidariedade, partilha e comunicação, as quais desafiam a lógica dominante e, justamente por isso, são "alvos" dos investimentos do poder. Expliquemos melhor essa configuração.

Em 1987, com o livro "Os novos espaços de liberdade", Guattari e Negri atentam para uma tendência mundial, que colaborou na produção de uma imagem de "vitória do capitalismo": 
Os regimes colectivistas que se reclamam do socialismo falharam rotundamente. Entretanto, a questão do capitalismo mantém-se. As promessas de liberdade, de igualdade, de progresso, de luz foram traídas tanto de um lado como de outro. As organizações capitalistas e socialistas tornaram-se cúmplices; conjugaram os seus esforços para estender sobre o planeta uma máquina imensa para escravizar a vida humana sob todos os aspectos - tanto os do trabalho como os da infância, do amor, da vida, tanto os da razão como os do sonho e da arte. (p. 5).

O que acontece, principalmente a partir da década de 1980, é que o regime soviético dito "comunista", tido como principal oponente ao modo de vida capitalista, foi exposto em toda sua ineficiência de operar o comunismo idealizado por Marx, perdendo terreno e tornando-se pouco eficaz em se perpetuar. Com a derrocada desse regime, foi difundida junto à opinião pública, de um modo geral, a ideia de uma completa hegemonia do sistema capitalista. Todavia, "ganhar a guerra" não significou o fim das batalhas e nem uma situação confortável para os governos que se rotulavam capitalistas. Fora dos holofotes, as lutas não estavam apaziguadas. Como nos aponta Martins (1999):

O socialismo soviético ruiu com o muro de Berlim, e seu principal antagonista, o bloco de países de economia capitalista ocidental, também se viu frente a uma crise que não expressa apenas uma conjuntura econômica procurando se rearticular, mas que, sobretudo, tomou um rumo imponderável: a política, a cultura, os valores, os movimentos sociais e a emergência de diferentes movimentos étnicos-religiosos configuram um caldo cultural que exige respostas emergências [sic]. (p. 87).

Segundo a mesma autora, tais respostas vêm, principalmente, da articulação de mecanismos supranacionais ${ }^{5}$ como 0 Banco Internacional de Reconstrução e Desenvolvimento (BIRD) e o Fundo Monetário Internacional (FMI), organismos que representam hoje os mais emblemáticos territórios de defesa da lógica capitalista. As promessas de "ajuda" para a "re-estruturação dos países" são acompanhadas por uma série de exigências que contribuem para a disseminação de valores afins com essa lógica. Não podemos pensar, entretanto, que para a maioria dos governos é sofrível executar tais exigências. O capitalismo, como nos apontam Deleuze e Guattari, é produção desejante ${ }^{6}$ : na verdade, podemos pensar que o BIRD e o FMI não apenas emprestam dinheiro, mas vendem, injetam, produzem valores que passam a ser almejados e perseguidos.

Tais valores constituem o pano de fundo, de meio e de frente para uma proliferação de reformas em vários países. No Brasil, somados ao apelo da necessidade de fortalecimento de nossa recentemente 
"recuperada democracia", culminam num conjunto que Frigotto (2001) designa por "projeto societário neoconservador", o qual implica, inclusive, a realização de reformas em diversos setores da máquina administrativa. Gostaríamos de destacar aqui as reformas empreendidas na educação. Estas têm sido concebidas, entre outras coisas, de forma a contribuir para uma produção de subjetividade propícia à criação e afirmação das condições de funcionamento capitalista.

Sendo assim, tais reformas, em sua concepção, estimulam o desenvolvimento de modos de subjetivação individualistas e competitivos, pautados em ideais como o de "autossuperação", tendo em vista a capacidade de produzir cada vez mais, com a maior qualidade possível, em situação de destaque em relação aos pares ou, nos termos corriqueiros, "concorrentes" -, o que oportunizará consumir cada vez mais, não apenas produtos, mas modos de vida. Com relação a isso, Linhares (2001, p. 153) nos instiga:

\begin{abstract}
Afinal, quem desconhece que com os processos de reorganização do sistema produtivo, em que a prioridade recai no uso intensivo de capital, tornou-se indispensável levar a população a se identificar com esses interesses acumulativos e concentradores?
\end{abstract}

Com relação a esse contexto, Saviani (2008) aponta algumas tendências atuais. Em tempos em que se admite não haver emprego para toda a população economicamente ativa, forma-se não mais para a conquista do emprego, mas para a empregabilidade, ou seja, para uma potencialidade de emprego e para uma busca individual incessante para a melhoria dessa empregabilidade. Tal funcionamento pode ser pensado como alienante, já que produz a ideia do indivíduo como responsável exclusivo de seu sucesso ou fracasso: se não se consegue emprego é porque se precisa ter um currículo melhor, é preciso estar mais capacitado. Tal autor aponta, ainda, que o profissional com alta empregabilidade é o que sabe "aprender a aprender", ou seja, não o que acumula conteúdos, mas o que está a cada dia buscando se atualizar; é o profissional dotado de competências que lhe permitirão dar soluções aos problemas do dia a dia de trabalho. Isso implica no desenvolvimento de uma distorcida "autonomia", já que os imperativos são para um movimento de produção do mesmo, ou seja, de respostas diferentes dentro de uma mesma lógica: produzir mais, aumentar a eficácia, ampliar os lucros... Busca-se criar condições para respostas imediatas, e pouco se fala em problematizar a ordem das coisas, o modo de vida que exclui a tantos e que impõe um ritmo que vem produzindo adoecimentos (DEJ OURS, 1992). 
Ora, e como fica a questão da comunidade nessa configuração? A partir das análises explicitadas acima, poderíamos seguir uma linha e dizer que a "comunidade não fica". Mas, como nos mostra Foucault, nem a vida e - por conseguinte - nem a história é linear (2008b). Entramos aí em nossa segunda formulação: não que a comunidade tenha sido relegada nos discursos hegemônicos, mas, de várias formas, seu sentido foi re-significado. Entendemos que ocorreu com a ideia de comunidade algo parecido ao que Guattari e Negri apontam com relação ao comunismo. Segundo eles: "Os modos de agir capitalísticos apropriaram-se do discurso do comunismo para o despojar da sua capacidade de análise e da sua força libertadora" (1987, p. 6).

Isso é estrategicamente muito importante para o funcionamento capitalista, dado que, como já mencionamos, ele não mantém um reinado muito confortável: se as coalizões de esquerda parecem ter sucumbido à causa capitalista, pululam, mundo afora, movimentos que buscam a criação e afirmação de novas formas de vida, de formas mais autônomas, mais solidárias, formas que escapam à fôrma do capital. Pululam também uma série de conflitos sociais, étnicos e religiosos ${ }^{7}$. A pobreza também pulula. Continuando a provocação de Linhares:

Quem não percebe que verdadeiros barris de pólvora constituídos pela 'população sobrante', habitando as ruas sem esperança e sem dignidade ou organizando rebeliões nos presídios - estão cada dia mais próximos de explodir? (2001, p. 153).

Face a isso, as políticas oficiais dos Estados capitalistas buscam constituir, por meio de propostas de intervenção que propagam o "desenvolvimento social" e a atenção às "demandas da comunidade" uma coesão social que garanta as bases de sua estabilidade política.

Desse mesmo modo, colaboram para a reprodução do regime as construções - frequentes nos atuais discursos oficiais do Estado que seguem o modelo "escola e comunidade devem caminhar juntas". Isso porque tal constructo polariza e dicotomiza escola e comunidade, como se fossem elementos separados, diferentes. Nessa lógica, escola e comunidade "caminhando juntas" equivale a menos conflitos e menos obstáculos a serem administrados.

Aguiar (2003) mostra como o constructo comunidade tem sido utilizado com finalidade similar no mercado de bens sociais de um modo geral, o qual:

[...] se utiliza desse código para eleger interlocutores, repassar verbas e financiamentos - governamentais e nãogovernamentais. Uma "comunidade organizada" tem sido um requisito constante para iniciar qualquer negociação 
tanto com o poder público, quanto com as entidades de fomento nacionais e internacionais. Mas um elemento chave que se espreita nessa imagem, é a existência de lideranças fortes e representativas que possam servir de mediadores e/ou apaziguadores de possíveis conflitos futuros. (p. 104).

Assim, começamos a observar um significativo aumento de práticas como as "consultas à comunidade", "parcerias com a comunidade", mas vemos sérios embaraços quando, por exemplo, irrompe um movimento de pais e/ou alunos numa escola.

Como salientou Valla (2002), os governos têm buscado se utilizar da participação popular para legitimar atos de sua gestão ou para solucionar problemas que simplesmente não dão conta de gerir. Acompanhando as análises do autor, não é de se estranhar que os espaços oficializados de participação nos governos, como o caso da maioria dos conselhos de saúde, estejam esvaziados e, desse modo, sejam pouco ou nada representativos. Na visão de Valla, tal conformação política funciona mais como controle social (controle dos aparatos governamentais, midiáticos, da propriedade privada sobre as decisões que incidem na população) do que como controle público (ações de controle da sociedade civil organizada e de caráter popular visando à melhoria da qualidade de vida da maioria da população).

Dessas análises, consideramos importante destacar um ponto que nos é fundamental: se é necessário ao capitalismo lançar mão de tantos aparatos de captura, é porque, como já afirmamos, há movimentos de resistência que estão sempre a incomodar e a se reinventar. Retomando Guattari e Negri (1987), entendemos que muitos espaços organizados justamente para traçar alternativas ao modo de vida impulsionado pela produção capitalista, como sindicatos e movimento estudantil, foram apropriados, em grande parte por esse mesmo sistema, segmentarizando, repartindo, estabelecendo prioridades de umbigo - prioridades que favorecem um determinado grupo em detrimento a outro. Mas, se as resistências vão manobrando o poder, outros espaços vão sendo forjados.

Entramos aqui em nossa terceira formulação sobre os movimentos contemporâneos das políticas de comunidade na educação e para isso nos utilizaremos de vivências nossas no espaço escolar, de experimentações que temos efetuado nas pesquisas que estamos realizando. Tomaremos uma questão - dentre outras tantas possíveis - para analisarmos o surgimento de novas políticas de comunidade no contemporâneo que escapam às cristalizações abordadas até este ponto do trabalho.

Temos percebido e - muitas vezes lamentado - o esvaziamento dos espaços formais de participação social não só na educação, mas em diversos outros campos de interesse público. Sem fazer apologia à extinção desse tipo de fórum, começamos a perceber que muitos 
deles sucumbiram a um certo peleguismo, ou "grudaram" em figuras passadas que não são muito eficazes no contemporâneo. Atentandonos para as molaridades, essa tendência parece apontar para o "esfriamento" das lutas em prol da efetivação de políticas realmente públicas. Todavia, lançando mão de um olhar micropolítico, podemos perceber outras lutas que têm se tecido com nuances muito sutis, 0 que, tendemos a considerar, fala de um refinamento das tecnologias de resistência. Para explicar essa formulação, lançamos mão das ideias de multidão e de produção do comum formuladas por Hardt e Negri (2005).

Segundo esses autores, multidão é diferente de povo e de massa; é ativa, não se caracteriza pela fragmentação, anarquia ou incoerência; é “um sujeito social internamente diferente e múltiplo cuja constituição e ação não se baseiam na identidade ou na unidade (nem muito menos na indiferença), mas naquilo que tem em comum" (HARDT; NEGRI, 2005, p. 140). Pensar em multidão implica num desafio para as ideias de soberania, já que ela se constitui como "carne viva que governa a si mesma", sendo, portanto "o único sujeito social capaz de realizar a democracia" (p. 141), a partir da mobilização do que esses autores designam por comum. "O comum não se refere a noções tradicionais da comunidade ou do público; baseia-se na comunicação entre singularidades e se manifesta através dos processos sociais colaborativos da produção" (p. 266).

$\mathrm{E}$, se a produção da multidão não é instituída, oficializada, cristalizada numa forma-entidade, é muito mais difícil de ser identificada e capturada nos jogos de poder capitalistas. Assim, não nos parece casualidade que esses novos tipos de vínculos subjetivos, essas redes que não se fixam em objetos ou lugares determinados, essa superfluidade dos encontros seja codificada como a "morte dos bons tempos de comunidade" (HARDT; NEGRI, 2005; PELBART, 2003; CESAR, 2007). Produz-se um sentimento de incompletude no contemporâneo, um desejo de agarrar-se a formas de convívio duradouras, quiçá eternas, como se tudo que escapasse disso fosse uma vida na indiferença.

O capital quer transformar a multidão numa unidade orgânica, assim como o Estado quer transformá-la num povo. [...] Mas a produção biopolítica da multidão tende a mobilizar o que compartilha em comum e o que produz em comum contra o poder imperial do capital global. (HARDT; NEGRI, 2005, p. 141).

Assim, enquanto se procura exclusivamente nos movimentos organizados e duradouros práticas de liberdade e o "lugar da resistência", deixa-se de perceber uma outra produção de comunidade: espaços efêmeros, modos de associação mais fluidos e não segmentarizados, pequenas lutas que vão modificando o 
cotidiano escolar. Na escola em que se realiza tal pesquisa encontramos esse tipo de política de comunidade na criação de fortes redes de solidariedade e partilha da vida, na agremiação que se faz pelas diferenças entre os muitos Outros que co-habitam o espaço escolar, as quais operam pequenas lutas sem partido que conseguem interferir nos processos de gestão.

\section{Criminalização da vida e escola: Outros fazeres possíveis ?}

Outras questões presentes no cotidiano escolar contemporâneo que valem a pena discutir, dizem respeito à judicialização da vida e à criminalização da pobreza. Temos abordado essas questões a partir de pesquisas que realizamos em escolas públicas, observando a intensificação da interlocução com o poder judiciário para arbitrar conflitos que emergem no cotidiano escolar.

Como anteriormente exposto, as políticas hegemônicas de comunidade têm servido muitas vezes ao controle da vida, à manutenção das desigualdades e ao funcionamento do capital, no entanto, não se trata apenas disso, é preciso estar atento também aos movimentos que rompem e produzem desvios nessa lógica. Os processos de criminalização da pobreza e judicialização da vida fazem emergir uma série de interrogações que ao serem colocadas em análise nos possibilitam reinventar nossas práticas e movimentar as forças presentes nesse contexto para produzir escapes.

Nesse sentido, aqui discutiremos os incômodos produzidos pela aproximação entre a escola e os processos de criminalização de práticas que permeiam seu cotidiano e também como, desse modo, a escola vai tecendo em meio às produções do social, discursos aliados ao controle e à lógica de captura da vida. É cada vez mais comum as escolas chamarem a polícia para fazer parte da condução dos conflitos que Ihe atravessam hoje, perpetrando em suas práticas um modo de vida pautado na lógica inquisitória do judiciário.

A vida no contemporâneo se configura sob outras/novas formas de funcionamento. Se a discussão atual traz a questão da liberdade sob o foco dos holofotes, devemos pensar que ela não é tão óbvia assim. A partir das discussões trazidas acerca da biopolítica, é possível pensar que formas de controle têm se engendrado atualmente a fim de que essa problematização nos forneça ferramentas de luta e possibilite a criação de outras práticas.

Deleuze (1992) nos ajuda a pensar essa questão quando diz que nas sociedades atuais o controle sobre a vida tem se tornado mais sutil e invisível e, portanto, descentralizado. Seus mecanismos estão presentes no cotidiano, controlando a vida em sua dimensão expansiva e inventiva, especialmente através de artifícios cada vez mais sofisticados, sem perder em eficácia e violência. Se antes o 
poder era localizável, fosse na figura do rei ou das instituições, hoje isso se desmancha e, dissipado, cria a impressão de que estamos sendo menos vigiados.

Retomando a noção de biopolítica, tal como colocada por Foucault (2007), podemos afirmar que ela consiste num conjunto de estratégias que vem se instalando sobre a vida numa perspectiva de preocupação com o homem enquanto membro de uma espécie. Surge para dar conta de uma urgência que não é a mesma das disciplinas (de lidar com uma massa ociosa, nômade; uma urgência de produção), mas a complementa no sentido de maximizar o controle sobre os processos da vida humana, por meio da organização e administração da cidade e dos fenômenos de massa.

No entanto, apesar de se configurar como um poder que se exerce sobre a vida, operando pela via do fazer viver, nunca se viram práticas (como é o caso do holocausto) tão sangrentas como a partir do século XIX (FOUCAULT, 2007). Diferente do poder soberano, no biopoder deixa-se morrer para fazer viver alguns, isto é, em nome de um certo modo de vida (hegemônico e, portanto, legitimado) "autoriza-se" o extermínio daqueles que podem ameaçá-lo. Deixar morrer, dessa forma, pode se referir tanto ao não provimento de melhores condições de vida para uma parcela da população, quanto ao extermínio propriamente dito. Nesse caso, é possível afirmar que se trata de uma prática de fazer morrer, mais do que deixar morrer.

Assim, não é qualquer população que pode ser descartada. Existe um processo histórico e cada vez mais intenso de produção de classes perigosas que podem, então, ser eliminadas pelo bem do restante. Tal artifício tem sido construído vinculando-se a população pobre à noção de perigo e/ou ameaça, como veremos a seguir.

Coimbra (2001) afirma que, a partir da década de 1980, diversos jornais começam a veicular de forma mais enfática a violência nas cidades brasileiras. Explicitando uma série de exemplos de reportagens, a autora mostra que esse momento coincide com o do crescimento das cidades e, consequentemente, do desemprego e da expansão da pobreza. Nesse sentido, as camadas pobres passam a ser alvo de políticas de Estado e de Governo, fato que evidencia que começavam a se tornar uma preocupação para a sociedade.

Tratava-se de uma população que se tornava, rapidamente, numerosa demais para ser assistida por práticas caritativas e, então, passava a ser enxergada como um problema crônico, especialmente pelo aumento do número de assaltos, furtos e roubos, associados à falta de condições financeiras atrelada ao desemprego (COIMBRA, 2001). Até hoje encontramos esse discurso presente em muitas falas. Tem sido discutido o fato de que o capitalismo neoliberal funciona tendo como uma de suas peças a mão-de-obra excedente, 0 que configura os índices cada vez mais altos de desemprego 
estrutural no mundo, mas parece-nos que muitos debates ainda têm apontado como cerne da questão social a falta de emprego.

$\mathrm{O}$ processo de construção do pensamento que vincula a pobreza à noção de periculosidade ${ }^{8}$ serve muito bem ao funcionamento do capital.

\begin{abstract}
O Estado cujas funções sociais são privatizadas passa a assumir papel estritamente policial, para assegurar a ordem que garanta a economia "estável" a cujos consumidores mantêm-se seguros e confiantes. Se, durante a década de 1960 a 1970, o Estado de bem-estar social (welfare state) foi o modelo de funcionamento estatal em países do capitalismo central, o neoliberalismo, durante os anos 1980, se impõe, e o Estado se sujeita cada vez mais ao mercado e, para tanto, diminui prerrogativas às áreas econômicas e sociais e, precisamente por isso, cujas intervenções aumentou e reforçou [sic] no âmbito da 'segurança', agora reduzida à dimensão criminal. (BOCCO, 2008, p. 116-117).
\end{abstract}

Este processo não está descolado de toda uma indústria sobre violência. Diariamente são transmitidas pelos principais meios de comunicação do país notícias com essa temática, que assustam e alarmam a população sobre a questão da segurança pública em diversas cidades, produzindo um clima de constante insegurança na vida das pessoas. Com isso, outras práticas cada vez mais violentas mas que não são veiculadas dessa forma, ou ainda, não são entendidas dominantemente como violentas -, intituladas como de segurança, vão sendo implementadas no cotidiano de nossas vidas. A produção desse medo faz com que se legitimem ações extremistas especialmente contra as populações pobres, configurando a desqualificação e descartabilidade dessas vidas (BATISTA, 2002).

Vemos, assim, a produção de formas-subjetividades moduladas no sentido do funcionamento do sistema neoliberal capitalista. Os meios de comunicação em massa, dos quais o sistema capitalista faz uso, veiculam, constantemente, notícias que ampliam sutilmente 0 controle sobre o que a população pensa, que tem como efeito mudanças sobre seus modos de vida. Essa forma de "controle a céu aberto" (DELEUZE, 1992) constitui, portanto, uma concepção generalizada de violência e crime. Cria-se a necessidade de uma intervenção, ainda que mais agressiva, forjando um estado de segurança que garanta a contenção do medo, sem que se perceba que esse medo também está sendo forjado. Esse estado de segurança também contribui para as tentativas de produção de coesão social às quais se refere Martins (1999), conforme já citado.

Portanto, ao falarmos de uma sociedade liberal nos remetemos a uma sociedade que legitima forças cada vez mais intensivas de controle da vida por meio de flexibilizações e modulações. Nesse sentido, os 
funcionamentos atuais do capital têm produzido agenciamentos com espaços legitimados da verdade, dentre eles o campo de poder-saber jurídico - suas práticas discursivas e não discursivas. Pode-se entender o processo de judicialização da vida, nesse contexto, como um mecanismo que se configura nos dias atuais, de controle mais disfarçado.

O termo judicialização quer dizer estar sob júdice, isto é, estar em julgamento. Compreende-se como judicialização da vida o movimento do/no contemporâneo no qual vemos emergir o Poder Judiciário como instituição mediadora da vida. Um dos aspectos que vem ao encontro desta formulação é que jamais foram vistas tantas ações serem levadas à Justiça como nos dias atuais. No entanto, esse termo denuncia mais do que o aumento do número de processos que chegam diretamente aos órgãos e instâncias propriamente jurídicas, como as figuras do Fórum, dos Juizados ou do juiz. Essa ampliação do direito e do poder judiciário tem se estendido por domínios antes habitados por outros saberes e práticas e aponta para um modo de vida que tem predominado no cenário atual. Segundo Bocco (2008):

Tal modelo, que opera em termos de julgamento, culpabilização e punição, não só está presente em todos os meios como totalmente naturalizado à sociedade, e se apresenta como forma a-histórica e como única opção possível, para enfrentar as tensões impostas pelo projeto neoliberal. (p.117).

Se pensarmos, portanto, que a judicialização não se compreende apenas como uma crescente demanda voltada ao Judiciário, podemos entender que esta é efeito de um modo de vida, em que nós temos exercido a função do tribunal sobre nós mesmos e funcionado, portanto, sob uma lógica que não permite negociações, meios-termos ou nuances. Trata-se de um processo de capilarização do funcionamento binário do tribunal nas diversas esferas da vida, se conjugando a um discurso que se aproxima cada vez mais da norma, da lei e do direito. Esse processo fica evidente quando observamos um retorno de práticas/discursos voltados ao enaltecimento da moral e da criminalização, que se entendia ter sido superado após o fim da ditadura militar na década de 1980, como é o caso das solicitações de medidas coercitivas mais incisivas em relação aos jovens, da diminuição da maioridade penal, da volta da disciplina de Moral e Cívica nas escolas e da criminalização dos movimentos sociais.

Tais forças conjuram o que podemos chamar de criminalização da vida: um processo, um movimento em que funcionamos como juízes da vida; tomando conta uns dos outros e endurecendo as ações contra aqueles que ameaçam a ordem. Somos juízes e polícia.

É interessante observar que o contexto histórico em que esse processo se expande e difunde coincide com o da ascensão do 
neoliberalismo como estrutura sócio-econômico-política mundial. $\mathrm{O}$ Estado de Bem-Estar Social é substituído por um Estado Penal (WACQUANT, 2001, 2003), mínimo nas questões sociais e máximo nas repressivo-punitivas, que se instaura como característica dos governos ocidentais a partir de meados da década de 1980. Nesse sentido, a ditadura do mercado, que impera muito além da economia, determina a existência de um Estado que assegure sua estabilidade, dando-Ihe a função de guardião da ordem e segurança. Com as políticas sociais predominantemente sob a função do mercado, ao Estado cabe eliminar o perigo que possa estremecer a confiança e segurança da classe consumidora. Segundo Deleuze (1992), "é verdade que o capitalismo manteve como constante a extrema miséria de três quartos da humanidade, pobre demais para a dívida, numeroso demais para o confinamento". Dentro dessa lógica, a pobreza vai se constituindo como uma ameaça a essa segurança por se configurar como uma parcela da população que aparentemente não se insere nessa máquina. Apesar disso, é fundamental atentar para o fato de que mesmo não parecendo estar incluído, esse segmento é necessário para fazer funcionar a máquina capitalista. Isto é, ao mesmo tempo em que existe uma população que entendemos ser excluída desse mecanismo por não possuir emprego fixo, renda estável, boas condições de moradia e saneamento, entre muitas outras coisas, é preciso colocar em cena que isso faz parte do próprio funcionamento do capital, da sua máquina que fabrica pobreza constantemente e necessita dela para fazer girar suas peças. Trazendo essa discussão para as questões colocadas hoje às escolas, entendemos que elas não poderiam estar isentas de toda essa produção, já que, como apontado anteriormente, a escola é tecida nas relações de poder (FOUCAULT, 2004) que constituem o campo social. Partindo dessas análises, perguntamos: como se tem entendido a questão da indisciplina atualmente? Como isso está ligado a essa discussão acerca da criminalização da vida? O que a suposta indisciplina dos alunos denuncia? O que faz com que recorramos aos recursos jurídicos para garantir um direito ou segurança na escola?

As questões trazidas até o momento mostram que este é um processo cada vez mais presente na vida escolar. Seja nas ameaças feitas aos alunos com a chamada do Conselho Tutelar, na presença regular de policiais na escola, na criminalização de comportamentos de alunos, na presença de facções do tráfico como atravessadores das relações na escola e na própria maneira de se lidar com os diferentes modos de viver que têm feito parte especialmente da escola pública e que, muitas vezes, confrontam com a formação e as condições de vida dos professores e funcionários. Tais ocorrências evidenciam alguns dos efeitos do processo de criminalização da vida, que produzem paralisações e impotências que permeiam o cotidiano 
dos educadores diante das referidas circunstâncias e que por isso solicitam a entrada de tais recursos a fim de dar conta daquilo que eles acreditam fugir de seu alcance.

A ideia de indisciplina, muito presente no cotidiano escolar, nos serve aqui como um analisador ${ }^{9}$ de toda essa discussão. Tal noção tem se associado com o processo de criminalização da pobreza e sido significada também como violência, tornando individual o campo de análises acerca dessa temática. A maior parte dos discursos acerca da indisciplina tem colocado o problema unicamente sobre o aluno, sua família e sua condição social, sem problematizar o modo de funcionamento escolar hegemônico e os modos de vida atuais. Os alunos pobres, moradores das favelas, são cotidianamente encarados como futuros bandidos, criminosos em potencial. $\dot{E}$ esse $O$ pensamento que vai se construindo e relacionando os comportamentos entendidos como indisciplinares ou de recusa/revolta diante da instituição escolar à noção de perigo.

\begin{abstract}
Se, para a compreensão do modo como se vem buscando enfrentar a complexidade do cotidiano escolar, acrescentarmos que a criança e o adolescente são vistos isoladamente do contexto, sendo portadores de diferentes carências e patologias, com características como a ambivalência, a fragilidade, a exposição a riscos e, nos casos das classes populares, a violência e a marginalidade, concluímos que o projeto educacional está ancorado em uma visão clínico-assistencial, ou seja, em cuidados e prevenção. Entre a avaliação de jovens carentes de senso crítico, de falta de amadurecimento e de jovens que potencialmente podem se constituir em forças marginais e violentas produzem-se as dependências dos educadores frente aos especialistas e a impotência de intervir ativamento no processo educacional. A indisciplina deixa de funcionar como mecanismo disparador de práticas politicamente articuladas, deixa de ser uma força que provoca reflexão e ação sobre o aluno concreto que temos, sobre as condições de ensino e as estratégias utilizadas, para se constituir como obstáculo ao processo de transformação que 0 ensino-aprendizagem pressupõe. (ROCHA, 2001, p. 219).
\end{abstract}

Dessa forma, há de se problematizar a noção de indisciplina para que possamos entender o que ela tem expressado. Rocha (2001) nos propõe a pensá-la como resistência a fim de nos provocar na criação de alternativas que realmente intervenham nessa lógica. Para a autora, a indisciplina é inerente ao processo educacional como forma de resistência frente ao aparelho normatizador e homogeneizador que a escola constitui. Encará-la como tensão produtiva, como afirmação da diferença potente do humano dá um outro tom a essa questão, providenciando ferramentas de trabalho e análise para a educação, 
como material para pensar o modo como a escola tem lidado com jovens atualmente.

Cabe, então, perguntar de que forma temos contribuído para tal prática nas escolas. Problematizando nossos discursos colocamos em cheque a forma como temos lidado com a temática da indisciplina e de que forma temos encarado as questões que atravessam esse cotidiano. Enfrentar a indisciplina com mais disciplina tem provocado adoecimentos (ROCHA, 2001) e levado a um empobrecimento das discussões acerca da própria função da escola nas sociedades contemporâneas, criando uma análise a-histórica acerca do problema.

A apreciação trazida nesse texto sobre os modos de controle que tem se exercido no contemporâneo, nos fornece ferramentas para a luta contra esses mecanismos por meio de estratégias também mais sutis. Seriam as estratégias de resistência figuradas nos movimentos sociais que ganharam força no Brasil a partir das décadas de 1970 ou 1980, o único caminho possível de luta nos dias atuais? É dessa forma que queremos continuar trabalhando nas escolas: transformando jovens em criminosos? Se o controle apresenta novas formas de funcionar, há também de se inventar novos modos de enfrentá-lo.

\section{Considerações finais}

As políticas hegemônicas de comunidade e os processos de criminalização da vida remetem a formas de contenção e controle contemporâneos. Mas, a partir da discussão das resistências, podemos pensar que junto a tais práticas se tecem produções que escapam a essas formas e que, justamente por isso, lhe conferem um caráter provisório. Desse modo, procuramos dar visibilidade também a esse tipo de produção que, em geral, está num plano invisível. Veyne (1998), ao discutir a ideia de práticas em Foucault, atenta para um processo de naturalização dos objetos, de invisibilização das práticas que os produzem: não conseguimos observar toda a produção engendrada pelas práticas, não as vemos em sua raridade, acreditando que as coisas são de determinada forma porque tal forma é natural. Ele chama isso de "a parte imersa do iceberg 'político'", não como o inconsciente freudiano, de natureza diversa a da consciência, ou o motor da história, como as relações de produção o são para Marx. A parte oculta do iceberg é apenas aquilo que está "abaixo da linha da visibilidade" (VEYNE, 1998, p. 251).

Nos trabalhos que temos desenvolvido em escolas, podemos perceber que, afastando um pouco o olhar do que é óbvio, procurando fazer com que esse nosso olhar não se volte apenas ao que nos induz às forças hegemônicas, várias produções de resistência se operam 
traçando outras políticas de comunidade, subvertendo as políticas do medo, instaurando, mesmo que provisoriamente, políticas de solidariedade, de invenção, de liberação.

Assim, entendemos, por exemplo, que, quando se instalam câmeras de segurança, todo um outro universo se instala "atrás das câmeras", se quebram as câmeras, se inventam modos mais sutis de agir e que não podem ser apreendidos por elas. $\mathrm{E}$ com isso não estamos valorando que "em frente à câmera" seja ruim e que "atrás da câmera seja bom". Não propomos também o fim dos sindicatos, dos movimentos organizados de participação social, mas entendemos que é preciso dar visibilidade a outras políticas de comunidade que se produzem no/pelo coletivo. O que buscamos mostrar nesse artigo é que a cada solução encontrada para aprimorar o controle, também se aprimoram as insubmissões.

\section{Referências}

AGUIAR, K. F. Ligações Perigosas e Alianças Insurgentes: Subjetividades e movimentos urbanos. 2003. $160 \mathrm{f}$. Tese (Doutorado em Psicologia Social) - Departamento de Psicologia Social, Pontifícia Universidade Católica de São Paulo, São Paulo.

BATISTA, V. O globo da morte. In: Rauter, C.; Passos, E.; Benevides, R. (Orgs.). Clinica e Política. Subjetividade e violação dos Direitos Humanos. Rio de Janeiro: Equipe Clínico-Grupal, Grupo Tortura Nunca Mais - RJ, Instituto Franco Basaglia/Editora Te Corá, 2002, p. 59-64.

BENEVIDES, R.; PASSOS, E. A humanização como dimensão pública das políticas de saúde. Interface - Comunicação, Saúde,

Educação, Botucatu, v. 9, n. 17, mar/ago 2005a.

BENEVIDES, R.; PASSOS, E. Humanização na saúde: um novo modismo? I nterface - Comunicação, Saúde, Educação, Botucatu, v. 9, n. 17, mar/ago 2005b.

BOCCO, F. A psicologia no Estado Penal: possibilidades e estratégias para subverter a judicialização. In: Coimbra, C.; Ayres, L.; Nascimento, M. L. (Orgs.). PI VETES. Encontros entre a psicologia e o judiciário. Curitiba: Ed. Juruá, 2008. p. 116-122.

CESAR, M. F. Como se existisse a humanidade. Revista do Programa de Pós-Graduação em Artes Visuais EBA - UFRJ, Rio de Janeiro, ano 14, n. 15, p. 17-25, 2007.

COIMBRA, C. Operação Rio: 0 mito das classes perigosas. Niterói/Rio de Janeiro: Intertexto/Oficina do Autor, 2001.

DEJ OURS, C. A loucura do trabalho: Estudo de psicopatologia do trabalho. Tradução de Ana Isabel Paraguay e Lúcia Leal Ferreira. 5. ed. São Paulo: Cortez-Oboré, 1992.

DELEUZE, G. Post-Scriptum sobre as sociedades de controle. In: 
Conversações. Rio de Janeiro: Ed. 34, 1992. p. 219 - 226. FöUCAULT, M. Aula de 24 de janeiro de 1979. In: Nascimento da Biopolítica. São Paulo: Ed Martins Fontes, $200 \overline{8}$. p.71-101.

Nietzsche, a Genealogia e a História. In:

Microfísica do Poder. Organização e tradução de Roberto Machado. 26. ed. Rio de Janeiro: Edições Graal, 2008b. p. 15-37.

História da Sexualidade I. 18. ed. Rio de Janeiro: Ed. Graal, 2007.

Ditos e escritos V. 2 ed. Rio de Janeiro: Ed. Forense Universitária, 2006.

O sujeito e o poder. In: DREYFUS, H. L.; RABINOW, P. Michel Foucault, uma trajetória filosófica: para além do estruturalismo e da hermenêutica. Tradução de Vera Porto Carrero. Rio de Janeiro: Forense Universitária, 1995. p. 231-249.

Método. In:

História da Sexualidade I: a vontade de saber. Rio de Janeiro: Graal, 1985. p. 88-97.

. Vigiar e Punir. 31a ed. Petrópolis, RJ, Ed. Vozes, 2006.

FRIGOTTO, G. Reformas educativas e o retrocesso democrático no Brasil nos anos 90. In: LINHARES, C. (Org.). Os professores e a reinvenção da escola: Brasil e Espanha. São Paulo: Cortez, 2001. p. 57-80.

GUATTARI, F.; NEGRI, T. Os novos espaços de liberdade, seguido de das liberdades na Europa e da carta arqueológica. Tradução da Editora Centelha. Coimbra: Centelha, 1987.

HARDT, M.; NEGRI, A. I mpério. Tradução de Berilo Vargas. 8. ed. Rio de Janeiro: Record, 2006.

Multidão. Guerra e democracia na era do I mpério. Tradução de Clóvis Marques. Rio de J aneiro: Record, 2005.

HECKERT, A. L. C. Narrativas de resistências: Educação e política. 2004. 313 f. Tese (Doutorado em Educação) - Universidade Federal Fluminense, Niterói, 2004.

LINHARES, C. Reformas educativas e o retrocesso democrático no Brasil nos anos 90. In: (Org.). Os professores e a reinvenção da escola: Brasil e Espanha. São Paulo: Cortez, 2001. p. 137-174.

MACHADO, L. D. Subjetividades contemporâneas. In: BARROS, M. E. B. (Org.). Psicologia: questões contemporâneas. Vitória: Edufes, 1999. p. 211-229.

MARTINS, A. M. A política do conhecimento: a identidade do saber e as reformas educativas. In: LINHARES, C. (Org.). Políticas do conhecimento: Velhos contos, novas contas. Niterói: Intertexto, 1999. p. 71-101.

NEGRI, A. Poder constituinte: o conceito de uma crise. In: . poder constituinte: ensaios sobre as alternativas da modernidade. Rio de Janeiro: Ed. DP\&A, 2002, p.7-56. 
NEVES, C. A. B. Gilles Deleuze e a Política: interferências nos modos de se estar nos verbos da vida (prelo). In: NASCIMENTO, M. L.; TEDESCO, S. (Org.). Ética e Subjetividade: novos impasses no contemporâneo. Porto Alegre: Sulinas, 2009. p. 192-213.

PELBART, P. P. A comunidade dos sem comunidade. In:

Vida capital: ensaios de biopolítica. São Paulo: Iluminuras, $\overline{2} \overline{0} \overline{3}$. $\bar{p}$. 28-41.

ROCHA, M. Educação e Saúde: coletivização das ações e gestão participativa. In: MAClEL, I. (Org.). Psicologia e Educação: novos caminhos para a formação. Rio de Janeiro: Ciência Moderna, 2001. p. 213-229.

ROLNIK, S. Cartografia sentimental: transformações contemporâneas do desejo. Porto Alegre: Sulina; Editora da UFRGS, 2006.

SAVIANI, D. O neoprodutivismo e suas variantes: neo-escolanovismo, neoconstrutivismo, neotecnicismo (1991-2001). In: História das idéias pedagógicas no Brasil. 2. ed. rev. e ampl. Campinas: Autores Associados, 2008.

VALLA, V. V. Prefácio: Controle social ou controle público? Uma contribuição ao debate sobre controle social. In: WENDHANSEN, A. $\mathbf{O}$ duplo sentido do controle social: (des)caminhos da participação em saúde. I tajaí: Univali, 2002.

VEYNE, P. M. Como se escreve a história: Foucault revoluciona a história. Tradução de Alda Baltar e Maria Auxiliadora Kneipp. 4. ed. Brasília: Editora Universidade de Brasília, 1998.

WACQUANT, L. As prisões da miséria. Rio de Janeiro: Jorge Zahar Editor, 2001.

Punir os pobres: a nova gestão da miséria nos Estados Ünidos. Rio de Janeiro: Revan, 2003.

\section{Endereço para correspondência}

Ana Lúcia C. Heckert

Universidade Federal do Espírito Santo, Vitória, Brasil. End: Rua Moacir Avidos, 63/401 Bloco B, Praia do Canto. Vitória - Espírito Santo. CEP: 29055-350

Endereço eletrônico: ana.heckert@gmail.com

Marcel Romanio

Universidade Federal do Espírito Santo, Vitória, Brasil. End: Rua Moacir Avidos, 63/401 Bloco B, Praia do Canto. Vitória - Espírito Santo. CEP: 29055-350

Endereço eletrônico: romanio135@yahoo.com.br

\section{Suzana Maria Gotardo}

Universidade Federal do Espírito Santo, Vitória, Brasil. End: Rua Moacir Avidos, 63/401 Bloco B, Praia do Canto. Vitória - Espírito Santo. CEP: 29055-350

Endereço eletrônico: sugotardo@yahoo.com.br

\section{Alessandra Speranza Lacaz}

Universidade Federal do Espírito Santo, Vitória, Brasil. End: Rua Moacir Avidos, 63/401 Bloco B, Praia do Canto. Vitória - Espírito Santo. CEP: 29055-350

Endereço eletrônico: a.slacaz@gmail.com 
Alessandra Speranza Lacaz, Marcel Romanio, Suzana Maria Gotardo,

Ana Lúcia C. Heckert

Questões contemporâneas no campo das políticas educacionais

Recebido em: 13/12/2010

Reformulado em: 14/06/2011

Aceito para publicação em: 27/06/2011

Acompanhamento do processo editorial: Deise Mancebo

\section{Notas}

* Mestre em Psicologia Institucional da Universidade Federal do Espírito Santo.

** Mestre em Psicologia Institucional da Universidade Federal do Espírito Santo.

*** Mestre em Psicologia Institucional da Universidade Federal do Espírito Santo.

*****Professora do Departamento de Psicologia e do Programa de Pós-Graduação em Psicologia Institucional da Universidade Federal do Espírito Santo.

${ }^{1}$ Partimos aqui do conceito de subjetividade desenvolvido por Deleuze e Guattari, o qual, como aponta Machado (1999), rompe com as ideias de personalidade, indivíduo e estrutura, por não remeter à unidade, à constância, a uma interioridade que se sobrepõe à exterioridade, mas a territórios existenciais que se criam e desfazem a partir de mecanismos históricos de um determinado momento e das particularidades de uma história de vida. Subjetividade, desse modo, não pode ser entendida em termos de essência, mas de produção.

${ }^{2}$ Segundo o autor, "O poder constituinte está ligado à ideia de democracia, concebida como absoluto. Portanto, o conceito de poder constituinte, compreendido como força que irrompe e se faz expansiva, é um conceito ligado à pré-constituição da totalidade democrática" (NEGRI, A. 2002, p.21).

${ }^{3}$ Macro e micropolítica, sob a perspectiva teórica institucionalista, não remetem a grandezas, mas modos de funcionamento que operam inseparavelmente, como um misto. Macro ou molar remete ao plano das formas, do que é visível a "olho nu", a configurações cristalizadas. Micro ou molecular remete ao plano dos fluxos, dos processos, das intensidades, que desestabilizam formas e produzem outras (ROLNIK, 2006).

${ }^{4}$ A ideia de "uso de si" acompanha as discussões de Foucault. Logo, não se trata de uma interioridade ou qualquer outro sentido de fechamento em si mesmo, mas ao contrário, trata-se de "[...] um exercício de si sobre si mesmo, através do qual se procura elaborar, transformar e atingir um certo modo de ser" (FOUCAULT, 2006, p.265).

${ }^{5} \mathrm{Com}$ relação a esses mecanismos supranacionais de dominação e captura, confira Hardt e Negri (2006).

${ }^{6}$ Neves (2009) explica que nas obras de Deleuze e Guattari o desejo é tomado como força motriz, não sendo propriedade de um sujeito, de um objeto e nem proveniente da falta. O desejo é colocado como produção não intencional, que ganha liga nos agenciamentos que efetua.

${ }^{7}$ Sobre esses movimentos, confira Hardt e Negri (2005).

${ }^{8}$ Refere-se a uma noção de perigo 'por vir', potencial.

${ }^{9}$ Este conceito é oriundo da Análise Institucional e expressa "acontecimentos que podem [...] fazer surgir, com mais força, uma análise; que fazem aparecer, de um só golpe, a instituição 'invisível'" (LOURAU, 1993). 